\title{
COMPARATIVE STUDY BETWEEN TWO DIFFERENT TYPES OF SOFT LINERS USED FOR PATIENTS WITH MAXILLARY OBTURATORS
}

\author{
Sahar A. Ghorab*
}

\begin{abstract}
This study compared two types of denture resilient liners, the first was acrylic resin based and the scond was silicone based liner when used in patients with maxillary obturators after partial maxillectomy has been done regarding microbial adhesion. Samples were collected from the fitting surface, laboratory procedures were done. Evaluation of microbial growth by scanning the vegitations surface area in relation to the total surface area of the petri dish using graduated transparent paper was done to study the microbial adhesion in both after two weeks and six weeks. The results showed that the effect of the material was of statistical significance while time was not. The silicone-based soft liner has more liability for microbial adhesion than acrylic resin-based soft liner. This could be attributed to the rough surface of the first material especially with time due to difference in surface topography which enhance the attachment of micro-organisms.
\end{abstract}

\section{INTRODUCTION}

Soft lining materials are used as adjunct to the practice of prosthetic dentistry to provide retention, stability, comfort and patient acceptance and satisfaction. It also helps in preservation of denture supporting structures. They enable energy to be absorbed by replacing the missing oral mucosa therefore reducing the load on the supporting tissues. Soft liners provide comfort for patients who cannot tolerate occlusal pressures such as patients with alveolar ridge resorption, soreness, knife edge ridge, deep undercuts, bony protuberances, bruxomania and cases with maxillary defects because of its cushioning effect which reduces functional stresses.

Soft liners achieve a more equal force distribution to reduce localized pressure .It also improve obturator retention by engaging undercuts and reducing the traumatic effect in patients with congenital or acquired defects due to its resiliency and good adhesion to denture or obturator base ${ }^{1}$

The clinical changes in visco-elasticity of soft lining material resulting from loss of plasticizers by dietary solvent and water sorption led to problems when using it due to changes in structures and properties. This will lead to swelling, distortion microbial adhesion and growth ${ }^{2}$

\footnotetext{
* Lecturer, Faculty of Oral and Dental Medicine,Cairo University.
} 
Several problems associated with use of soft denture liners including bond failure between the liner and the appiience base, loss of softness, porosity and poor tear strength ${ }^{3}$

The increased porosity of resilient liners during clinical use can lead to plaque accumulation and candida albicans colonization. It is a fact that dental materials which are exposed to oral invironments are immediately covered by salivary constituents and later on by oral micro-organisms.

Four phases during microbial adhesion have been identified: 1-transport to the surface. 2- Initial adhesion. 3-Attachment and 4- colonization. Surface roughness, aging and free surface energy have been found to influence these phases continuously and significantly with time ${ }^{1}$.

In (2008), Bal et al. ${ }^{4}$ made a pilot study to evaluate the adhesion of oral micro -organisms to temporary soft lining materials and to acrylic resin denture base surfaces. They concluded that, bacteria and candida showed more adherence to soft liners than to acrylic resin, This adherence increased continuously and significantly with time.

In patients who had tumor excision and acquired a maxillary defect, post nasal secretions affect the nature of oral flora which indirectly affect the microbial adhesion to the prosthesis surface. When soft lining materials are used for maxillofacial prosthesis, they are exposed to nasal secretions in addition to saliva. which together form a pellicle proving a receptor site for adherence of microorganisms especially yeast as nasal secretions have low $\mathrm{PH}$ which provide a suitable medium for its growth . Fungal colonization was observed frequently which started 3 months after insertion ${ }^{5}$ .Fungal colonization was assessed visually due to formation of significant plaque layer. The results are supported by Hannel et al. ${ }^{6}$ They concluded that with aging of soft lining material, there is increase in microbial adhesion and surface free energy.
Kawano et $\mathrm{al}^{6}$. evaluated the cushioning effect of soft liners, indicating that soft liners reduced the impact force during function.

Russell et al. ${ }^{7}$ mentioned that use of soft liner in oral cancer patients with postoperative defects requiring obturation and to modify transitional prosthesis after stage I \& II implant surgery is usually a must.

The most common problems encountered with denture liners use are water sorption and solubility ${ }^{8}$. These two problems cause changes in structure and properties of the material leading to swelling then distortion and roughness due to leaching out of plasticizers which enhance microbial adhesion and growth $^{9,10,11,12,13}$.

The aim of this study was to compare two different soft lining materials which are:

Bosworth Dentusil silicon-based liner and Ever soft acrylic-based liner regarding microbial adhesion and growth when used in patients with acquired maxillary defects and using maxillary obturators .

\section{MATERIALS AND METHODS}

10 patients were selected from the outpatient clinic, Faculty of Oral and Dental Medicine ,Cairo University for this study. They all have maxillary acquired defects (Fig.1). Acrylic resin temporary maxillary obturators were done for each .After secondary impression and pouring the master cast ,four equal squares of baseplate wax of $5 \mathrm{~mm}$ width were prepared and fixed at the defect side of the master cast then duplication was done before proceeding in setting up ,packing and curing of the obturators .

At the time of delivery ,the fitting surface at the defect side has four square cavities of five millimeter width which will be cleaned thoroughly using alcohol. Then filling two of these cavities with the 


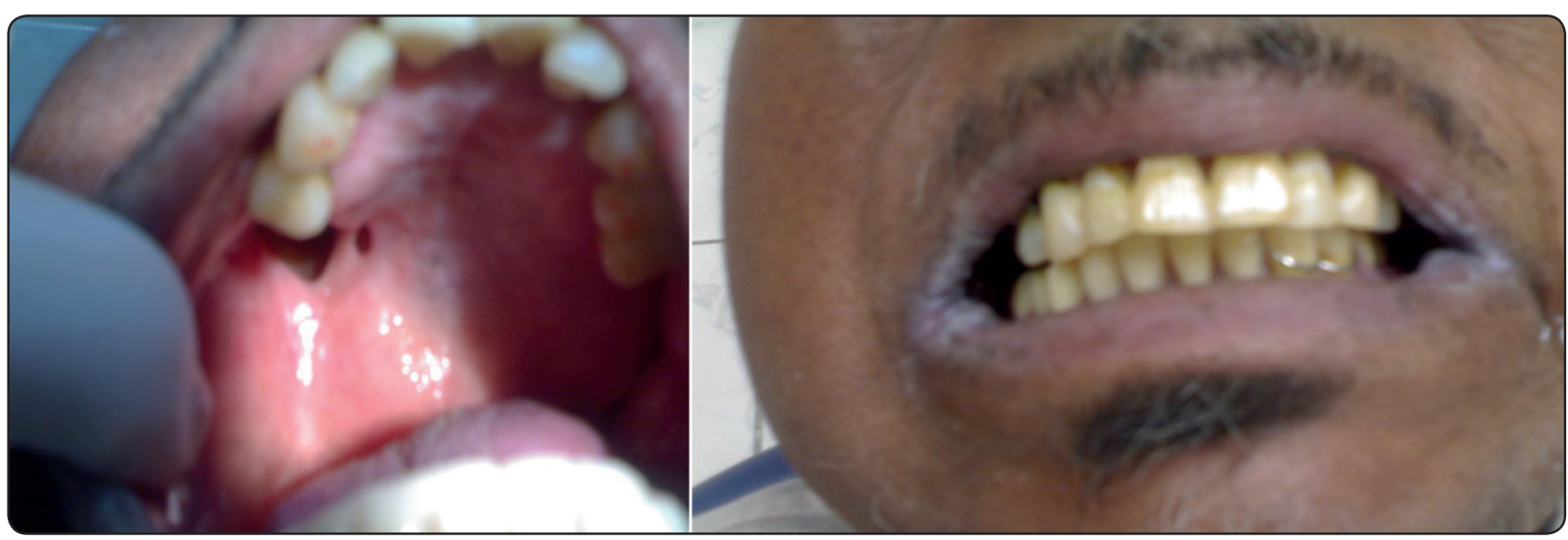

Fig (1) Cases with maxillary acquired defects.

first lining material which is Eversoft* acrylic resin -based soft liner (Fig.2) then inserting the obturator in the patient mouth and asking the patient to close in centric for one minute . removing the obturator from the patient mouth, immersing it in boiled water to cure for ten minutes after that, chilling it in cold water was done, removing the excess with sharp scalpel then finishing the edges with acrylic bur and rubber point.

Then applying the sealer and use dry and warm air for 2-3 minutes. The other two squares will be filled with Bosworth Dentusil** silicon- based liner (Fig.3) after applying the adhesive evenly using brush and leaving it for one minute to dry.

Inserting the cartridge into the gun then dispensing the material over the square areas of the obturator fitting surface then placing it in the patients mouth asking them to close in centric for 5-7 minutes to set .

Remove it from the patients mouth then allow 5 minutes for bench setting, trim the excess with scalpel and smoothen it with the polishing stone.

\section{Collecting the samples :}

For each patient four samples were collected,

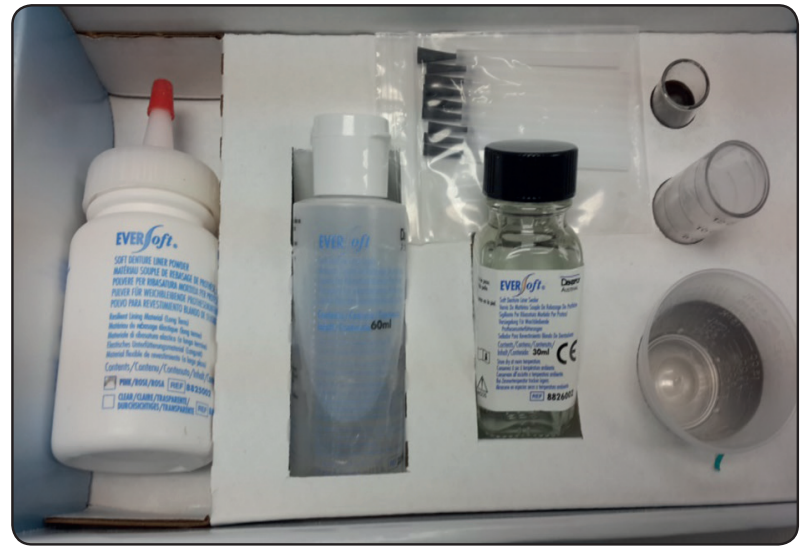

Fig. (2) Eversoft acrylic-based soft liner.

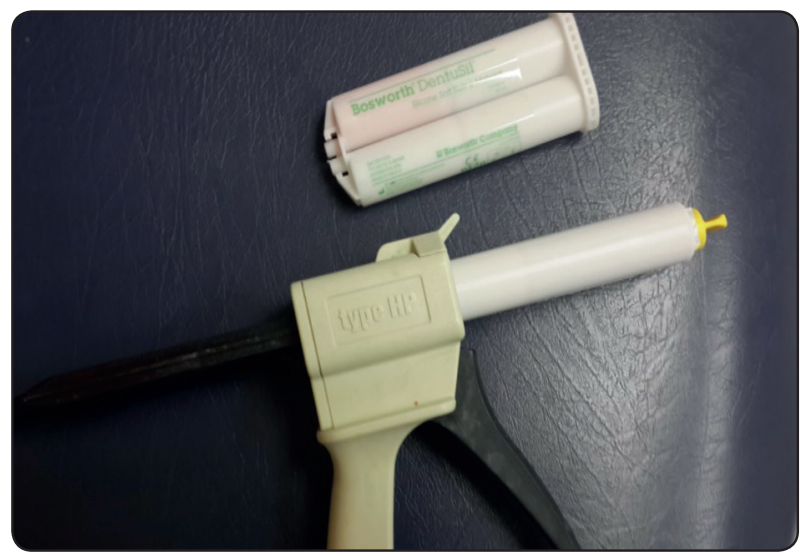

Fig.(3) Bosworth Dentusil silicon-based soft liner two for each material, the first two samples were

*DENTSPLY International Inc.,Austenal,York,PA17405-0872,1-800-621-0381,USA,www.austenal dentsply.com. ** The Harry J. Bosworth Company 7227North Hamin Avenue Skokie IL 60076-3999,USA.. 
collected two weeks after delivery ,while the second two samples were collected six weeks after delivery, one for each material.

Collecting the samples was done using sharp scalpel and bur .

\section{Studying the microbial adhesion:}

Each sample was collected in a test tube filled with20 milliliter of distelled water and sent to laboratory. The sample tubes were vortexed for 30 seconds then $0.01 \mathrm{ml}$. of each suspention was inoculated in blood agar dish at 37 degrees for 48 hours (Fig. 4)

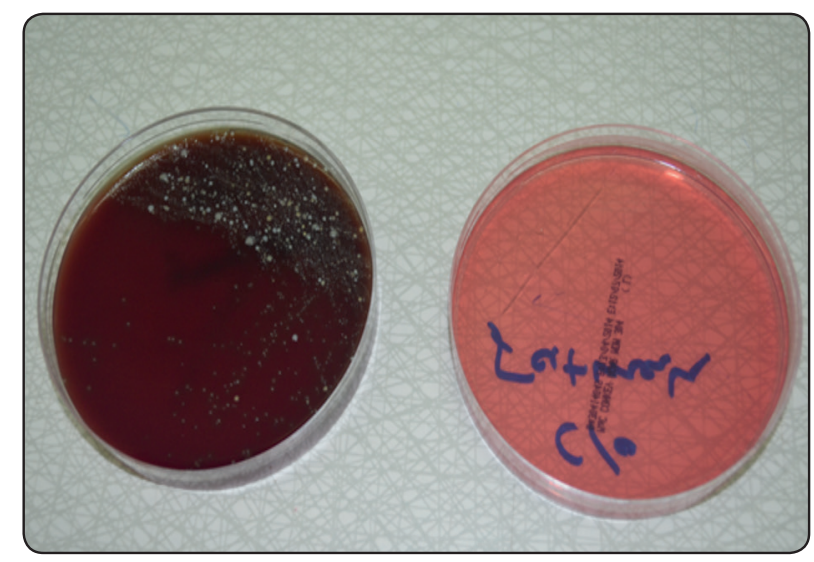

Fig. (4) : Micobial vegitations on blood agar plate.

Evaluation of microbial growth by scanning the vegitations surface area was done in relation to the total surface area of the petri dish using graduated transparent paper .

Repeating the same procedure for each patient for the four samples. Two samples after two weeks, one for each material and the other two after six weeks one for each material too.

Collected data were tabulated and statistically analyzed by calculating the mean and standard deviation for each tested material.

\section{RESULTS}

The mean and standard deviation values were calculated for each group in each test. Data were explored for normality using Kolmogorov-Smirnov and Shapiro-Wilk tests and showed parametric (normal) distribution.

Independent sample t-test was used to compare between two groups in non-related samples.

The significance level was set at $\mathrm{P} \leq 0.05$. Statistical analysis was performed with IBM $®$ SPSS ${ }^{\circledR}$ Statistics Version 20 for Windows.

\section{A) Effect of material in each time record:}

\section{First record (Two weeks):}

There was a statistically significant difference between (Silicone based liner) and (Acrylic based liner) where $(p=0.042)$.

The highest mean value was found in (Silicone based liner) $(41.55 \% \pm 13.26)$, the lowest mean value was found in (Acrylic based liner) $(30.15 \% \pm 9.79)$.

\section{Second record (Six weeks):}

There was a statistically significant difference between (Silicone based liner) and (Acrylic based liner) where $(p=0.017)$.

The highest mean value was found in (Silicone based liner) $(46.97 \% \pm 12.43)$, the lowest mean value was found in (Acrylic based liner) $(34.12 \%$ \pm 9.29 ).

\section{B) Effect of time of record in each material:}

\section{Silicone based liner:}

There was no statistically significant difference between (First record) and (Second record) where $(p=0.358)$.

The highest mean value was found in (Six weeks) $(46.97 \% \pm 12.43)$, the lowest mean value was found in (Two weeks) $(41.55 \% \pm 13.26)$. 


\section{Acrylic based liner:}

There was no statistically significant difference between (First record) and (Second record) where $(p=0.365)$.

The highest mean value was found in (Six weeks) $(34.12 \% \pm 9.29)$, the lowest mean value was found in (Two weeks) $(30.15 \% \pm 9.79)$

TABLE (1): The mean, standard deviation (SD) values of $\%$ of different materials in each time period.

\begin{tabular}{|c|c|c|c|c|c|}
\hline \multirow{3}{*}{ Variables } & \multicolumn{4}{|c|}{ Microbial growth \% } & \multirow{3}{*}{$p$-value } \\
\hline & \multicolumn{2}{|c|}{ Two weeks } & \multicolumn{2}{|c|}{ Six weeks } & \\
\hline & Mean & SD & Mean & SD & \\
\hline $\begin{array}{c}\text { Silicone } \\
\text { based liner }\end{array}$ & $41.55^{\mathrm{aA}}$ & 13.26 & $46.97^{\mathrm{aA}}$ & 12.43 & $0.358 \mathrm{~ns}$ \\
\hline $\begin{array}{c}\text { Acrylic } \\
\text { based liner }\end{array}$ & $30.15^{\mathrm{bA}}$ & 9.79 & $34.12^{\mathrm{bA}}$ & 9.29 & $0.365 n s$ \\
\hline p-value & \multicolumn{2}{|c|}{$0.042 *$} & \multicolumn{2}{|c|}{$0.017 *$} & \\
\hline
\end{tabular}

*; significant ( $p \leq 0.05) \quad n s ;$ non-significant ( $p>0.05)$, Superscripts with different small letters indicate statistically significance difference within the same column. Superscripts with different capital letters indicate statistically significance difference within the same row.

\section{C) Effect of material regardless of time period:}

There was a statistically significant difference between (Silicone based liner) and (Acrylic based liner) where $(p=0.002)$.

The highest mean value was found in (Silicone based liner) $(44.26 \% \pm 12.82)$, the lowest mean value was found in (Acrylic based liner) (32.13\% \pm 9.51$)$.

TABLE (2): The mean, standard deviation (SD) values of microbial growth $\%$ of different materials regardless of time.

\begin{tabular}{|l|c|c|}
\hline \multirow{2}{*}{ Variables } & \multicolumn{2}{|c|}{ Microbial growth \% } \\
\cline { 2 - 3 } & Mean & SD \\
\hline Silicone based liner & $44.26^{\mathrm{a}}$ & 12.82 \\
\hline Acrylic based liner & $32.13^{\mathrm{b}}$ & 9.51 \\
\hline p-value & \multicolumn{2}{|c|}{$\mathbf{0 . 0 0 2}^{\mathrm{b}}$} \\
\hline
\end{tabular}

*; significant ( $p \leq 0.05) \quad n s ;$ non-significant $(p>0.05)$, Superscripts with different letters indicate statistically significance difference within the same column.

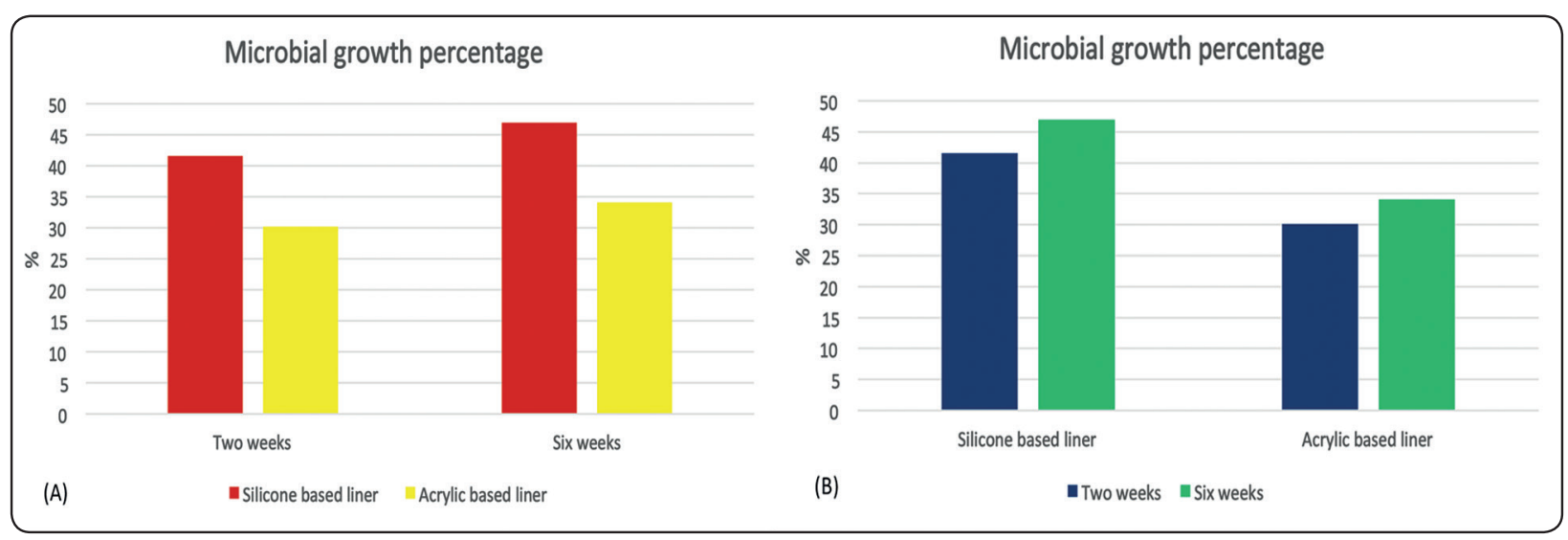

Fig. (5) Bar chart representing means of microbial growth $\%$ of different materials in each time period 


\section{Interaction between Materials and Time factor:}

Data in table (3) shows the results of Twoway ANOVA analysis for the effect of different variables. The results showed that Materials had a statistically significant effect at P-value 0.002. Time in the presence of material factor have no statistically significant effect at P-value $=0.198$. The interaction between the two variables had no statistically significant effect $\%$ at $\mathrm{P}$-value $=0.840$.

TABLE (3) Results of Two-way ANOVA for the effect of different variables on microbial growth percentage.

\begin{tabular}{|c|c|c|c|c|c|}
\hline $\begin{array}{c}\text { Source of } \\
\text { variation }\end{array}$ & $\begin{array}{c}\text { Type III } \\
\text { Sum of } \\
\text { Squares }\end{array}$ & Df & $\begin{array}{c}\text { Mean } \\
\text { Square }\end{array}$ & $\begin{array}{c}\text { F- } \\
\text { value }\end{array}$ & $\begin{array}{c}\text { P- } \\
\text { value }\end{array}$ \\
\hline Materials & 1470.399 & 1 & 1470.399 & 11.471 & $0.002^{*}$ \\
\hline Time period & 220.618 & 1 & 220.618 & 1.721 & $0.198 \mathrm{~ns}$ \\
\hline $\begin{array}{c}\text { Materials x } \\
\text { Time factor } \\
\text { interaction }\end{array}$ & 5.300 & 1 & 5.300 & 0.041 & $0.840 \mathrm{~ns}$ \\
\hline
\end{tabular}

$d f:$ degrees of freedom $=(n-1), *$ Significant at $P \leq 0.0$

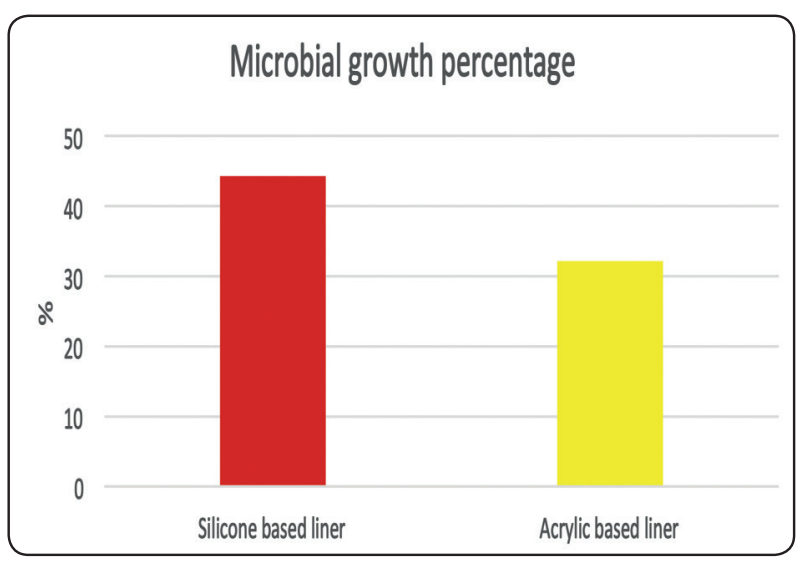

Fig. (6): Bar chart representing means of microbial growth \% of different materials regardless of time

\section{DISCUSSION}

The results of this study showed that the effect of the material was of statistical significance while time was not. The silicone-based soft liner has more liability for microbial adhesion than acrylic resin-based soft liner. This could be attributed to the rough surface of the first material especially with time due to difference in surface topography which affect the attachment of micro-organisms. Surface irregularities would increase the liability of microbial retention on it. ${ }^{14}$

Dental materials exposed to oral environment are immediately covered with salivary secretion and oral flora. This oral biofilm is the cause of many conditions such as caries, periodontal diseases and denture stomatitis. ${ }^{15}$

Rough surface of soft liner resulted in more colonization due to many small cracks which provided larger protected areas for colonization.

During cells colonization, acidic substance is produced as a metabolic byproduct which affect the surface $\mathrm{PH}$ which also increase the aggregation and adhesion of more layers ${ }^{16}$ Vural et al. $2010^{17}$ concluded that energy between surface particles of denture liner generate and facilitate cells adhesion. When surface roughness is increased, it enhance microbial adhesion.

When soft liners are used for maxillofacial prosthesis, they are exposed to nasal in addition to oral secretions. Surface energy and aging are also factors that increase the amount of microbial adhesion. They also concluded that specimens with artificial nasal secretion yielded a less C. Albicans adherence compared to artificial saliva. therefore nasal secretion with $\mathrm{Ph} 4.8$ causes less candida adherence which may be due to presence of NaNo3 in this medium that might had inhibited colonization $^{18,19}$.

However, they used the two types of secretion separately while in clinical situation the two types are there together. 
Our study also showed that with interaction between time and material there was no statistically significant difference from the first to the second record.

However the follow-up period was not enough, More investigations should be done.

\section{CONCLUSION}

Improvement in quality of denture liner regarding bond strength by creation of roughness of acrylic interface using laser or alumina abrasion or by surface chemical itching and oxygen plasma ${ }^{20,21}$. Also techniques to prevent microbial overgrowth by addition of silver nanoparticles due to its antimicrobial effect and low toxicity. ${ }^{22,23,24}$ Also incorporation of antifungal agent and use of sealer coating to alter the surface texture and make it smoother and decrease water sorption and leaching out of plasticizers. Reducing fungal colonization on the surfaces and improving mechanical strength may further improve the clinical performance of soft liners ${ }^{25,26}$.

\section{REFERENCES}

1- Al -Athel, M. and Jagger, R.G.: Bond strength of resilient lining materials to various denture base resins. Int. J. Prosthodont., 9(2)167-170,1996.

2- Williamson, R.T.; Clinical application of soft denture liner: A case report. Quintessence Int., 26:413-418,1995.

3- Clarke,D.A.:Resilient lining materials. Dent.Tech.,28:132137,1975 .

4- Bal, B.T., Yavuzyilmaz, H. and Yucel, M.: A pilot study to evaluate the adhesion of oral micro-organisms to temporary soft lining materials, J.Oral.Sci.,Mar.,50(1): $1-8,2008$.

5- mutluay, M.M., Oguz, S., Floystrand, F., Saxegaard, E., Dogan, A.,Bek,B.and Ruyter,I.E.:A prospective study on the clinical performance of polysiloxane soft liners :Oneyear Results,Dent, Mater. J.,27(3):440-447,2008.

6- Kawano, F., Kon, M., Koran, A., Matsumoto, N.: Shock -absorbing behavior of four processed soft denture liners . J. Prosthet. Dent.,72:599-605,1994.

7- Russell, E.A.JR.: Management of mucoepedermoid carcinoma of the palate .Report of case ,Oral Surg., Oral Med., Oral Pathol.,41:436-440,1976.
8- Collis J.: Assessment of a recently introduced fluroelastomeric soft lining material. Int. J. Prosthodont., 6:440-445, 1993.

9- Kawano, F., Dootz, E.R., Koran, A. and Craig,R.G.: Sorption and solubility of $12 \mathrm{soft}$ denture liners. J. Prosthet. Dent. 72:393-398,1994.

10- Waters, M.G., Jagger, R.G. and Winter, R.W.: Water sorption of (RTV)silicone denture soft lining material. J. Dent.,24:105-108,1996.

11- Emmer TJ Jr, Emmer TJ Sr, Vaidynathan TK.: Bond Strength of permanent soft denture liners bonded to the denture base. J. proshet. Dent.;90:595-6011992.

12- Eick JD, Craig RG, Peyton FA. Properties of resilient denture liners in simulated mouth conditions .J Proshet Dent 1962;12:1043-52

13- Kawano, F., Dootz, E.R., Kroon, A. 3rd. and Craig, R.G.: Comparison of bond strength of six soft denture liners to denture base resin. J. Prosthet. Dent. 68:368-371,(1992).

14- Verran, J., Maryan, C.J.: Retention of Candida albicans on acrylic resin and silicon of different surface topography. J. Prosthet. Dent., 77:535-539,1997.

15- Hahnel, S., Rosentritl, M., Handel, G. and Burgers ,R.:In Vitro Evaluation of artificial aging on surface properties and early candida albicans adhesion to prosthetic resins , J. Mater. Sci. Mater. Med.,2008.

16- Karaagaclioglu, L., Can, G., Yilmaz, B., Ayhan, N., Semiz, O. and Levent, H.: The adherence of candida albicans to acrylic resin reinforced with different fibers J. Mater.Sci.: Mater.Med.,19:959-963,2008.

17- Vural, C., Ozdemir, G., Kurtulmus, H., Kumbuloglu, O. and Ozcan, M.: Comparative effects of two different artificial body fluids on candida albicans adhesion to soft lining materials. Dental Material J., 29(2):206-212, 2010.

18- Shifman, A.: Clinical application of visible light-cured resin in maxillofacial prosthetics part 1: Denture base and reline material. J. Prosthet. Dent., 64: 578-582,1990.

19- Grubb, B.R., Chadburn, J.L. and Boucher, R.C.: In vivo microanalysis for determination of nasal liquid ion composition. Am.J.Physiol.282:1423-1431,2002.

20- Zhang, H., Fang, J., Hu, Z., Ma, J., Han,Y. and Bian, J.: Effect of oxygen plasma treatment on the bonding of a soft liner to an acrylic resin denture material. Dent. Mater.J.29(4):398-402,2010. 
21- -Mese, a.: Bond strength of soft denture liners following immertion of denture cleanser ,Biotechnol. \&Biotechnol. Eq.,20:184-191, 2006.

22- Fan ,C., Chu, L., Rawls, H.R., Norling, B.K., Cardenas, H.L. and Whang, K.: Development of an antimicrobial resin : a pilot study. Dent. Mater. J. ,27(4):322-328,2011.

23- Chaldek, G., Barszczewska, R.I. and Lukaszczyk, J.: Developing the procedure of modifying the denture soft liner by silver nanoparticles. Acta Bioeng. Biomech., 14(1):23-29, 2012.

24- Okita, N., Orstavik, D., Orstavik, J. and Ostby, K.: Invivo and in vitro studies on soft denture materials: microbial adhesion and tests for antibacterial activity. Dent.Mater. 7,155-160, 1991.

25- Jin, C., Nikawa, H., Makihira, S., Hamada, T., Furukawa, M. and Murata, H.: Changes in surface roughness and colour stability of soft lining materials caused by denture cleansers. J. Oral Rehabil., 30; 125-130, 2003.

26- Pratt-Rippin, K. and Pezzlo, M.: Identification of commonly isolated aerobic gram-positive bacteria. In clinical microbiology procedures handbook. Isenberg HDed. American Society for Microbiology. Washington, 20-28, 1992. 